\title{
Improved Characterization of Nod Factors and Genetically Based Variation in LysM Receptor Domains Identify Amino Acids Expendable for Nod Factor Recognition in Lotus spp.
}

\author{
Anita S. Bek, ${ }^{1,2}$ Jørgen Sauer, ${ }^{1,3}$ Mikkel B. Thygesen, ${ }^{1,3}$ Jens $\varnothing$. Duus, ${ }^{4}$ Bent O. Petersen, ${ }^{4}$ \\ Søren Thirup, ${ }^{1,2}$ Euan James, ${ }^{5}$ Knud J. Jensen, ${ }^{1,3}$ Jens Stougaard, ${ }^{1,2}$ and Simona Radutoiu ${ }^{1,2}$ \\ ${ }^{1}$ Centre for Carbohydrate Recognition and Signalling (CARB) and ${ }^{2}$ Department of Molecular Biology, University of Aarhus, \\ Gustav Wieds Vej 10, Aarhus 8000 C, Denmark; ${ }^{3} \mathrm{GGM}$, Faculty of Life Sciences, University of Copenhagen, \\ Thorvaldsensvej 40, DK-1871 Frederiksberg C, Denmark; ${ }^{4}$ Carlsberg Laboratory, Gamle Carlsberg Vej 10, 2500 Copenhagen \\ Valby, Denmark; ${ }^{5}$ EPI Division, Scottish Crop Research Institute (SCRI) Invergowrie, Dundee DD2 5DA, U.K.
}

Submitted 30 June 2009. Accepted 9 September 2009.

Formation of functional nodules is a complex process depending on host-microsymbiont compatibility in all developmental stages. This report uses the contrasting symbiotic phenotypes of Lotus japonicus and L. pedunculatus, inoculated with Mesorhizobium loti or the Bradyrhizobium sp. (Lotus), to investigate the role of Nod factor structure and Nod factor receptors (NFR) for rhizobial recognition, infection thread progression, and bacterial persistence within nodule cells. A key contribution was the use of $800 \mathrm{MHz}$ nuclear magnetic resonance spectroscopy and ultrahigh-performance liquid chromatography coupled to quadrupole-time-offlight mass spectrometry for Nod factor analysis. The Nod factor decorations at the nonreducing end differ between Bradyrhizobium sp. (Lotus) and M. loti, and the NFR1/NFR5 extracellular regions of $L$. pedunculatus and $L$. japonicus were found to vary in amino acid composition. Genetic transformation experiments using chimeric and wild-type receptors showed that both receptor variants recognize the structurally different Nod factors but the later symbiotic phenotype remained unchanged. These results highlight the importance of additional checkpoints during nitrogen-fixing symbiosis and define several amino acids in the LysM domains as expendable for perception of the two differentially carbamoylated Nod factors.

Rhizobial Nod factors and their plant receptors play a major role in the process of legume-rhizobia recognition (Denarie et al. 1996; Radutoiu et al. 2003) and this recognition process is also involved in determining host range and strain specificity (Radutoiu et al. 2007). In Lotus japonicus, two LysM receptor kinases, L. japonicus Nod factor receptor (NFR) 1 (LjNFR1) and LjNFR5, perceive the rhizobial Nod factor signal. Loss-offunction mutants are nodulation deficient $\left(\mathrm{Nod}^{-}\right)$and their root

L. pedunculatus $N f r 1$ and $N f r 5$ genomic sequence data is available in the EMBL datatbase under accession numbers FN424262 and FN424263.

Corresponding author: Simona Radutoiu; E-mail: sir@mb.au.dk

* The $\boldsymbol{e}$-Xtra logo stands for "electronic extra" and indicates that supplementary material comprising seven figures, three tables, and additional Materials and Methods information is published online. Also, Figures 1 and 4 appear in color online. hairs do not respond with the usual deformations observed in wild-type plants. The early electrophysiological responses such as calcium influx and calcium spiking were either absent or attenuated, and no infection thread or cortical cell division were initiated (Madsen et al. 2003; Radutoiu et al. 2003). In Medicago truncatula and Pisum sativum mutations in the LjNfr5 orthologs, MtNfp and PsSym10, respectively, cause a phenotype comparable with the Ljnfr5 mutants (Walker et al. 2000; Madsen et al. 2003; Arrighi et al. 2006). In contrast, the phenotype caused by inactivation of the MtLyk3 and PsSym37 genes encoding LjNFR1-type receptors differs from the Ljnfrl mutant phenotype. The $M t L y k 3$ gene is required for tight root hair curling, bacterial microcolony formation at the infection pocket, and infection thread initiation. Unlike the Ljnfrl mutants, cortical cell divisions were also initiated in the Mtlyk3 mutants. A weak allele of this gene ( $h c l-4)$ was impaired in infection thread progression and most infection threads were arrested in the epidermal cell layer in sac-like structures; therefore, LYK3 was suggested to function as an entry receptor (Limpens et al. 2003; Smit et al. 2007). In pea, the Sym37 gene regulates infection thread initiation and nodule development from cortical cell division foci (Zhukov et al. 2008). Rhizobia express the Nod factor biosynthetic genes when induced by plant (iso)flavonoids and they continue to express these genes when contained in the infection threads (Sharma and Signer 1990; Schlaman et al. 1991). Receptors exclusively involved in perception of Nod factor during infection thread progression have not been identified in Lotus spp. (as opposed to Medicago truncatula and pea), suggesting a possible role of LjNFR1 and LjNFR5 receptors not only in early recognition but also during infection thread progression and bacterial persistence in the nodule cells.

Previous experiments transferring the Lotus LjNfrl and LjNfr5 genes into M. truncatula showed a function for these receptor genes as host determinants. The Lotus spp. microsymbiont $M$. loti was capable of triggering nodulation and infection thread initiation in the nonhost $M$. truncatula carrying the two Lotus genes. Similarly, the LjNfrl and LjNfr5 receptor genes also served as host determinants in the Nod factordependent recognition of the Rhizobium leguminosarum bv. viciae DZL strain that distinguishes between two closely related species by nodulating L. japonicus but not L. filicaulis. A detailed analysis of this specificity using chimeric receptors, 
consisting of the extracellular domain from L. filicaulis and the kinase domains from L. japonicus transformed into Ljnfrl and Ljnfr5 mutants, identified a single amino acid in the LysM2 domain of the putative LjNFR5 Nod factor binding site that is involved in distinguishing Nod factors from DZL and M. loti strains (Radutoiu et al. 2007).

The rhizobia that nodulates Lotus spp. constitute a diverse group of strains encompassing fast-growing $M$. loti strains and slow-growing Bradyrhizobium strains (Scott et al. 1985) but, thus far, only the structure of Nod factors produced by $M$. loti strains are described (Lopez-Lara et al. 1995). Most M. loti strains form nitrogen-fixing $\left(\mathrm{Nod}^{+} \mathrm{Fix}^{+}\right)$nodules on $L$. corniculatus and $L$. tenuis. In contrast, $M$. loti forms ineffective $\left(\mathrm{Nod}^{+} \mathrm{Fix}^{-}\right)$nodules on a more distantly related species, L. pedunculatus (Degtjareva et al. 2006). A slow-growing strain of Bradyrhizobium has the opposite phenotype and infects $L$. pedunculatus effectively $\left(\mathrm{Nod}^{+} \mathrm{Fix}^{+}\right)$while $L$. corniculatus and $L$. tenuis develop ineffective nodules with this strain (Scott et al. 1985; Petit et al. 1987).

Here, we addressed the question of Nod factor perception by LjNFR1 and LjNFR5 receptors during several stages of legume-rhizobia symbiosis, using the biodiversity described among Lotus spp. and their interactions with different rhizobial strains. As a necessary prerequisite, we used improved analytical methods, including ultrahigh-performance liquid chromatography (UPLC)-quadrupole-time-of-flight mass spectrometry (Q-TOF MS) and $800 \mathrm{MHz}$ nuclear magnetic resonance (NMR) spectroscopy with a cryoprobe in order to assign structures and abundances of individual Nod factor species. Extending the experimental approach of genetic complementation (Radutoiu et al. 2007) using more distantly related Lotus spp., we analyzed the properties of Nod factor and NFR influencing early recognition, infection thread progression, and bacteroid persistence in infected root nodule cells.

\section{RESULTS}

\section{Bradyrhizobium sp. (Lotus) and M. loti infect Lotus spp. differently.}

In order to determine the symbiotic relationship between the model legume L. japonicus and Bradyrhizobium sp. (Lotus) more precisely, we performed a detailed analysis of the symbiotic phenotype. The number of nodules, their infection status and nitrogen-fixing capacity measured by acetylene reduction, and the shoot growth was determined for plants inoculated with Bradyrhizobium sp. (Lotus). We compared these phenotypic characteristics to the phenotype of $M$. loti-inoculated plants (Figs. 1 and 2). Like M. loti, Bradyrhizobium sp. (Lotus) induced nitrogen-fixing root nodules on L. japonicus (Fig. 1A, B, E, and F). However, Bradyrhizobium sp. (Lotus)-induced nodules had a lower acetylene reduction capacity and the plants showed limited shoot growth compared with $M$. loti-inoculated control plants. The number of functional nodules was reduced and the number of white, ineffective nodules significantly increased on plants inoculated with Bradyrhizobium sp. (Lotus) compared with M. loti (Fig. 2A). L. pedunculatus was also able to form nodules with both M. loti and Bradyrhizobium sp. (Lotus) (Fig. 1C, D, G, and H). However, on this species, the Bradyrhizobium sp. (Lotus) was able to induce an efficient nitrogenfixing symbiosis, whereas $M$. loti inoculation resulted in development of supernumerary small, white, uninfected root nodules (Figs. 1G and 2B). No acetylene reduction was detectable and the plants were clearly nitrogen starved (Supplementary Figs. S1 and S2).

Bradyrhizobium bacteria initiated the nodule developmental program on L. japonicus roots, and infection threads invading the nodule tissue were formed (Fig. 1I). This shows that L. ja- ponicus recognizes the Nod factors produced by the slow-growing Bradyrhizobium sp. (Lotus). However, time-course inoculation experiments showed that the onset of Bradyrhizobium sp. (Lotus) nodulation occurred with a 1-week delay compared with $M$. loti, and that the first functional nodules emerged with a 4-week delay (Fig. 2C). Detailed electron microscopy (transmission electron microscopy) of pink nodules revealed very few intact symbiosomes inside the infected nodule cells, and early senescence was pronounced (Fig. 1I). This early senescence is also observed in the time-course inoculation experiment where the number of pink nodules remained constant up to 14 weeks postinoculation while a continued increase was observed for a functional symbiotic interaction (Supplementary Fig. S3). At this late developmental stage, characterized by symbiosome formation and function, the compatibility between the two partners appeared to cease and, consequently, the plants showed signs of nitrogen-limited growth.

To examine whether these differences between the $M$. lotiand Bradyrhizobium sp. (Lotus)-induced L. japonicus nodules

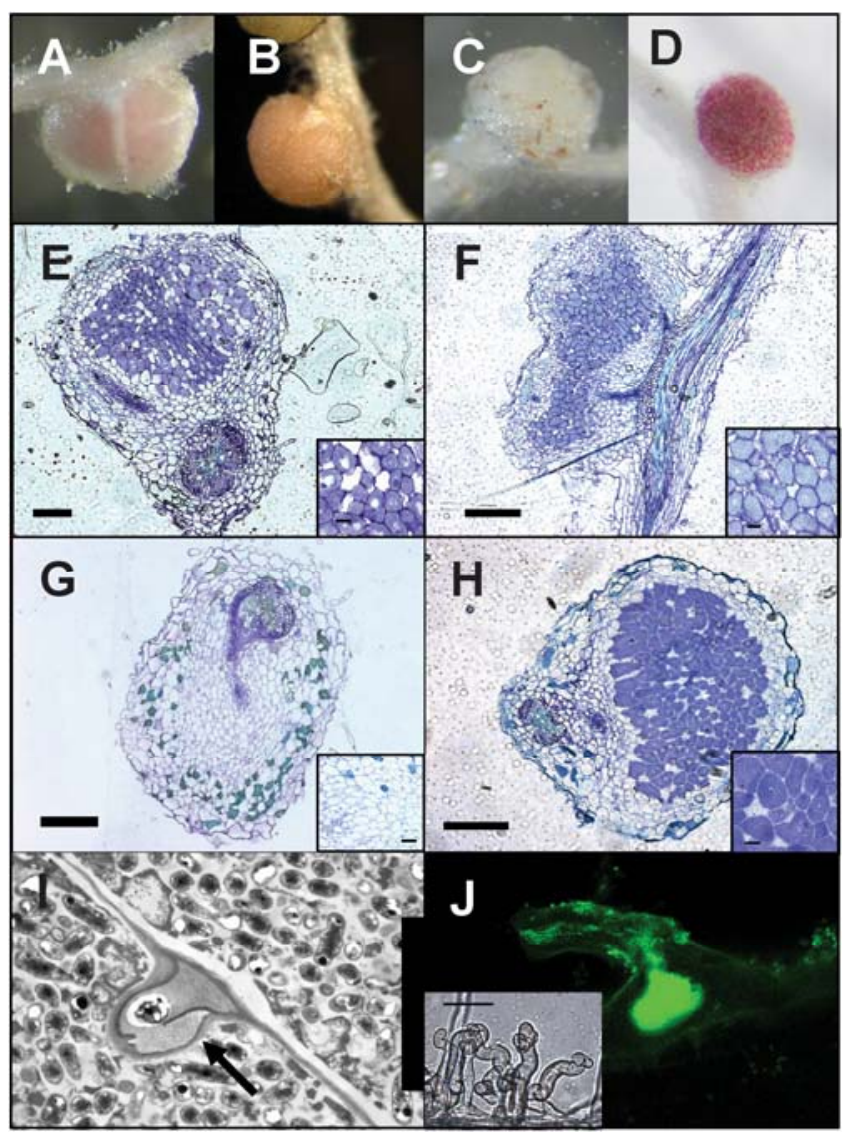

Fig. 1. Symbiotic phenotypes induced by rapid- and slow-growing rhizobia on Lotus roots. A, Mesorhizobium loti induced nodule on Lotus japonicus. B, Bradyrhizobium sp. (Lotus)-induced nodule on L. japonicus. C, M. lotiinduced nodule on L. pedunculatus. D, Bradyrhizobium sp. (Lotus)-induced nodule on $L$. pedunculatus. E, Toluidine-blue-stained section of $M$. lotiinduced nodule on L. japonicus. F, Toluidine-blue-stained section of Bradyrhizobium sp. (Lotus)-induced nodule on L. japonicus. G, Toluidine-bluestained section of $M$. loti-induced nodule on L. pedunculatus. $\mathbf{H}$, Toluidineblue-stained section of Bradyrhizobium sp. (Lotus)-induced nodule on $L$. pedunculatus. $\mathbf{E}$ through $\mathbf{H}$, Close-ups of the central nodule cells are shown in the insets. I, Electron micrograph of Bradyrhizobium sp. (Lotus)-induced L. japonicus nodule ( 3 weeks old). Arrow shows infection thread containing one degraded bacteroid. J, M. loti enhanced-green fluorescent proteininduced infection thread stopped in the epidermal cell layer. The inset shows root hair curling of $L$. pedunculatus upon inoculation with $M$. loti. Scale bars: E through H, $200 \mu \mathrm{m}$; insets of E through H, J, and I, $50 \mu \mathrm{m}$ (transmission electron microscopy micrograph) $\times 6,000$. 
were reflected at the level of gene regulation, expression of six nodulin genes was monitored by quantitative real-time polymerase chain reaction (PCR). The selected genes were previously shown to be upregulated during later stages of nodule development. The $L j L b 3$ gene is one of the three symbiotic leghemoglobin genes transcribed upon bacterial entry and required for nitrogenase activity (Ott et al. 2005). Nin encodes a putative transcription factor crucial for both nodule and infection thread development (Schauser et al. 1999). The symbiotic sulfate transporter LjSstl is upregulated during the symbiotic interaction with $M$. loti, and mutation in this gene results in early senescent nodules, a phenotype similar to the phenotype of L. japonicus nodules induced by Bradyrhizobium sp. (Lotus) (Krusell et al. 2005). LjNod21 (N21) and LjNod 65 (N65) are two late nodulin genes previously found upregulated in nodule tissue (Szczyglowski et al. 1997). The LjGln1 gene encodes a cytosolic glutamine synthetase expressed in roots and nodules of Lotus spp. (Thykjaer et al. 1997) and might

\section{A L.japonicus B L.pedunculatus}

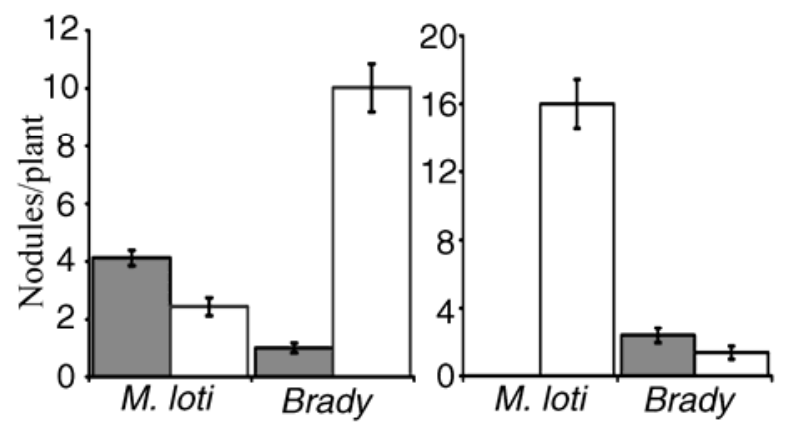

C
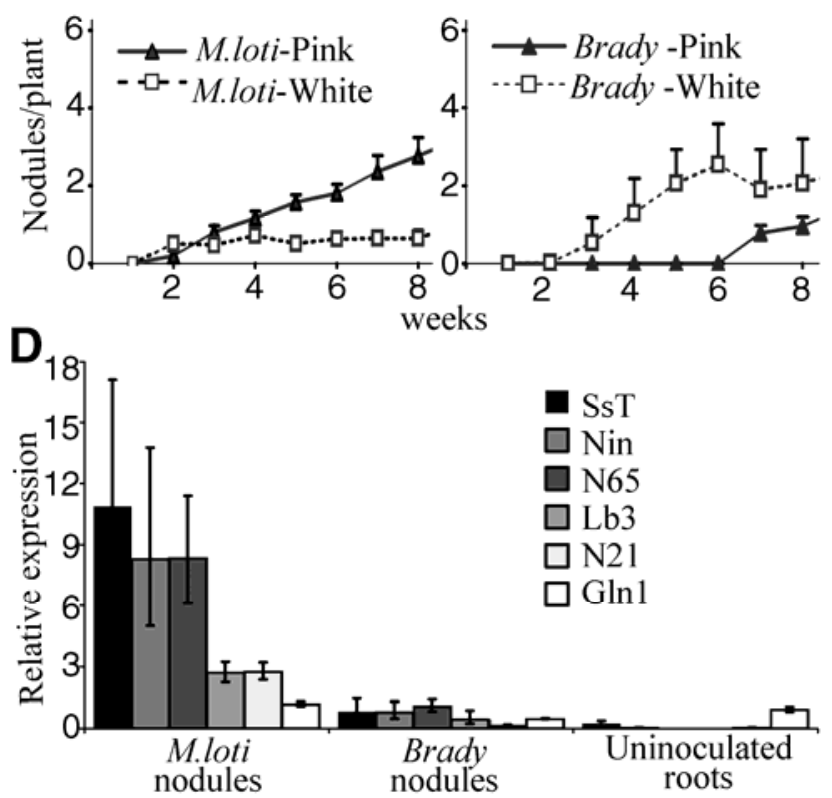

Fig. 2. Nodulation and nodulin gene expression in Lotus spp. inoculated with Bradyrhizobium sp. (Lotus) or Mesorhizobium loti. Number of white (white) and pink (gray) nodules induced by M. loti and Bradyrhizobium sp. (Lotus) on A, Lotus japonicus and B, L. pedunculatus. C, Time course of nodulation of L. japonicus roots inoculated with either Bradyrhizobium sp. (Lotus) or M. loti. D, Relative expression levels of nodulin genes in $L$. japonicus nodules induced by M. loti or Bradyrhizobium sp. (Lotus) nodules. SsT $=$ L. japonicus sulfate transporter; Nin $=$ LjNin; $\mathrm{N} 65=$ L. japoni cus nodulin65; Lb3 = L. japonicus leghemoglobin3; N21 = L. japonicus nodulin21; Gln $1=$ L. japonicus glutamin synthetase. Error bars represent the $95 \%$ confidence interval. have a role in assimilation of fixed nitrogen (Miflin and Habash 2002). Five of the six tested nodulins were found to be upregulated in both types of nodules when compared with the uninoculated roots, showing that nodulin genes were induced by both rhizobia. However, compared with the $M$. loti nodules, all tested genes had significantly lower transcript levels in the Bradyrhizobium sp. (Lotus) nodules (Fig. 2D). The lower levels of leghemoglobin and Sstl in Bradyrhizobium sp. (Lotus) nodules of L. japonicus might explain their pale-pink appearance (Krusell et al. 2005).

$L$. pedunculatus plants inoculated with $M$. loti initiated the nodule developmental program, and supernumerary small white nodules emerged (Figs. 1C and 2B). Five weeks after inoculation, these nodules were still uninfected (Fig. 1G) and the plants were nitrogen starved. Microscopical analysis of $L$. pedunculatus inoculated plants with an enhanced-green fluorescent protein (eGFP)-labeled $M$. loti revealed that the root hair responses and infection pocket formation occurred but the infection process was stopped in the root hair where thickened infection threads ended in sac-like structures in the epidermal cells (Fig. 1J).

Based on the results obtained from the morphological and molecular analyses of the symbioses induced by the fast-growing M. loti and slow-growing Bradyrhizobium sp. (Lotus) on the two Lotus spp., we can conclude that, in Lotus plants, recognition of rhizobia as compatible symbionts takes place in at least three steps. Both of the tested rhizobial strains passed the initial epidermal recognition (step 1) leading to root hair deformation and curling (Fig. 1J), and the nodule developmental program was induced on both legume species. M. loti infection of L. pedunculatus stopped at the root cortex (step 2) (Fig. 1J), whereas Bradyrhizobium sp. (Lotus) infection of L. japonicus resulted in premature senescing nodules with reduced nitrogen fixation efficiency (step 3). The ability of these two legume species to initiate nodulation with the different genera of rhizobia led us to investigate the molecular basis of the recognition process.

\section{Bradyrhizobium sp. (Lotus) and M. loti produce different Nod factors.}

The structure of $M$. loti Nod factors was previously reported (Lopez-Lara et al. 1995); however, for the symbiotic partner of L. pedunculatus, the Bradyrhizobium sp. (Lotus), the chemical structure of the Nod factor was unknown. We took advantage of improved NMR technology in order to identify the type of Nod factors produced by Bradyrhizobium sp. (Lotus) and precisely identify the position of decorations on the $M$. loti Nod factor. A genetically modified strain carrying the naringenin-inducible nodD activator (Pacios Bras et al. 2000) was grown to ensure Nod factor production upon induction. The preparative high-performance liquid chromatography (HPLC) profile of the Bradyrhizobium sp. (Lotus) butanol-extracted Nod factors semipurified over Varian BondElut C18 extraction columns consists of one peak (peak 1) which elute between 45 and 50\% acetonitrile. The corresponding extract from $M$. loti elutes as two peaks in the same interval of acetonitrile (Supplementary Fig. S4). The fraction originating from the $\mathrm{C} 18$-extraction column was subjected to analysis by UPLC on reverse-phase columns with $1.7-\mu \mathrm{m}$ particle size for high resolution coupled with detection by highly sensitive Q-TOF MS for identification (Table 1; Fig. 3; Supplementary Fig. S5). The structural characterization of Nod factor ornamentation was achieved using an $800-\mathrm{MHz}$ NMR spectrometer equipped with a cryoprobe using HSQC, HMBC, and H2BC (Petersen et al. 2006) C-H correlation experiments on the fraction of Nod factors eluted in peak 1 . This revealed closely related but not identical structures for 
the two major types of Nod factors produced by $M$. loti and Bradyrhizobium sp. (Lotus). In both cases, positions 3 and 4 on the fucosyl moiety (reducing end) contain either an acetyl attached or a hydrogen. In the nonreducing end, the Bradyrhizobium sp. (Lotus) Nod factor has two carbamoyl groups attached to positions 3 and 6 , whereas $M$. loti has only one on position 3. Both M. loti and Bradyrhizobium sp. (Lotus) Nod factors have an N-methylated cis-vaccenic acid (C18:1) attached to the nonreducing end 2-amino group of the analyzed peak 1 (Fig. 4; Supplementary Tables S2 and S3). Analysis of the $\mathrm{C} 18$ semipurified fraction revealed several minor species in both Bradyrhizobium sp. (Lotus) and M. loti preparations, including species that correspond to a stearic acid (C18:0) attached to the 2-amino group of the terminal nonreducing GlcNAc (Table 1).

Isolated Nod factors (peak 1) from the Bradyrhizobium sp. (Lotus) were compared with the M. loti Nod factors for their biological activity by performing an in planta assay using the Nin-Gus L. japonicus plant line (Radutoiu et al. 2003). Both types of Nod factors induced Nin promoter activity in the susceptible zone of $L$. japonicus roots; however, $M$. loti was slightly more efficient (18 of 29 roots) compared with the Bradyrhizobium sp. (Lotus) (14 of 32 roots).

\section{L. japonicus and $L$. pedunculatus show major differences in the NFR amino acid composition.}

In order to determine whether the receptor-mediated recognition of the Nod factors might be responsible for the symbiotic phenotype of Bradyrhizobium sp. (Lotus) and M. loti, the L. pedunculatus, LpNfrl, and LpNfr5 receptors were identified. We sequenced PCR products obtained using L. pedunculatus genomic DNA as template and primers derived from the corresponding L. japonicus genes. Alignment of the predicted L. pedunculatus and L. japonicus NFR domains revealed the presence of several amino acid differences between the ex- tracellular domains of the receptors from the two species. In NFR1, 12 of 17 amino acid differences are located in the predicted extracellular region and 5 of them are within the LysM domains (Fig. 5A). In the NFR5, 14 of 28 amino acid differences are present in the predicted extracellular region, and eight of these are located in the LysM domains (Fig. 5B; Supplementary Fig. S6). This large variation between the NFR extracellular regions of the two species corresponds with their taxonomical position in two separate phylogenetic clades (Degtjareva et al. 2006). For both NFR1 and NFR5, the second LysM domain is the most divergent, a feature that was previously observed when different orthologous and paralogous LysM-RLK were compared (Arrighi et al. 2006; Radutoiu et al. 2007; Zhang et al. 2007).

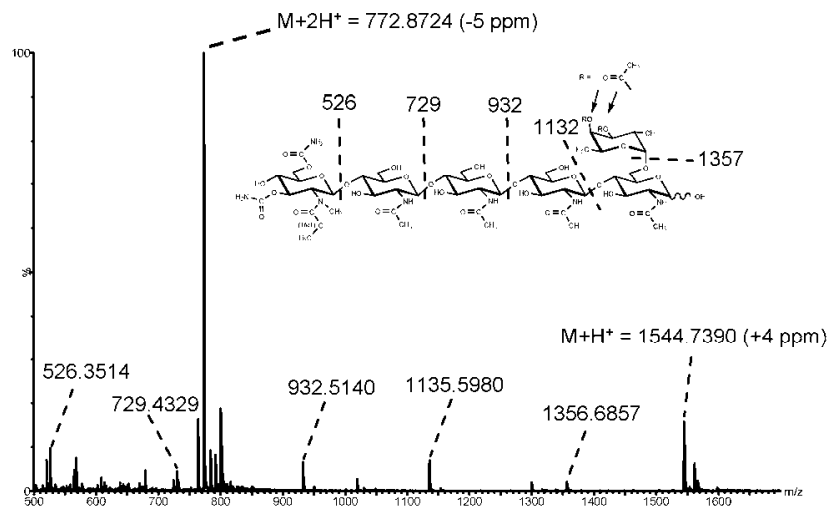

Fig. 3. Mass spectrometry analyses of Nod factors purified from a Bradyrhizobium sp. (Lotus). Fragmentation sizes of the saturated and unsaturated forms are shown. The masses are extracted in a time window of 6.4 to $7.2 \mathrm{~min}$. Values indicated on the inset originate from either the single protonated full mass, the double protonated full mass, in-source fragmentation, or $\beta$-elimination.

Table 1. Mass spectral data of Nod factors produced by Mesorhizobium loti and Bradyrhizobium sp. (Lotus) detected by ultrahigh-performance liquid chromatography coupled to quadrupole-time-of-flight (UPLC/Q-TOF)

\begin{tabular}{|c|c|c|c|c|c|c|c|c|c|}
\hline \multirow[b]{2}{*}{ Rhizobium $^{\text {b }}$} & \multirow[b]{2}{*}{$\operatorname{Mass}^{\mathrm{c}}$} & \multirow[b]{2}{*}{$\mathbf{M}+\mathbf{H}+{ }^{\mathbf{d}}$} & \multicolumn{5}{|c|}{ Fragments $^{\mathbf{a}}$} & \multirow{2}{*}{$\begin{array}{c}\text { Nonreducing } \\
\text { end Glc-NAc }\end{array}$} & \multirow{2}{*}{$\begin{array}{r}\begin{array}{r}\text { Reducing } \\
\text { end Fuc. }\end{array} \\
\mathrm{C}_{3} \mathrm{C}_{4}\end{array}$} \\
\hline & & & $\mathbf{B}_{1}$ & $\mathbf{B}_{2}$ & $\mathbf{B}_{3}$ & $\mathbf{B}_{4}$ & $\mathbf{B}_{5}$ & & \\
\hline \multicolumn{10}{|c|}{ Bradyrhizobium sp. (Lotus) NZP 2309} \\
\hline \multicolumn{10}{|l|}{ Unsaturated form } \\
\hline Minor components & $\begin{array}{l}1,458.7216 \\
1,500.7321\end{array}$ & $\begin{array}{l}1,459.7360(+5) \\
1,501.7443(+3)\end{array}$ & $\begin{array}{l}483.3439(+1) \\
483.3414(-4)\end{array}$ & $\begin{array}{l}686.4232(+1) \\
686.4268(+6)\end{array}$ & $\begin{array}{l}889.5027(+6) \\
889.5028(+7)\end{array}$ & $\begin{array}{l}1,092.5881(+6) \\
1,092.5952(+13)\end{array}$ & $\begin{array}{l}1,313.6821(+9) \\
1,313.6823(+9)\end{array}$ & $\begin{array}{l}\mathrm{C}_{16: 1} \mathrm{Cb}, \mathrm{OH}^{\mathrm{e}} \\
\mathrm{C}_{16: 1} \mathrm{Cb}, \mathrm{OH}^{\mathrm{e}}\end{array}$ & $\begin{array}{l}\mathrm{OH} \mathrm{OH} \\
\mathrm{Ac}, \mathrm{OH}^{\mathrm{e}}\end{array}$ \\
\hline Major components & $\begin{array}{l}1,501.7274 \\
1,543.7379\end{array}$ & $\begin{array}{l}1,502.7300(+3) \\
1,544.7390(+4)\end{array}$ & $\begin{array}{l}526.3501(+2) \\
526.3514(+4)\end{array}$ & $\begin{array}{l}729.4343(+8) \\
729.4329(+6)\end{array}$ & $\begin{array}{l}932.5122(+5) \\
932.5140(+6)\end{array}$ & $\begin{array}{l}1,135.5907(+3) \\
1,135.5980(+9)\end{array}$ & $\begin{array}{l}1,356.6769(+0) \\
1,356.6857(+7)\end{array}$ & $\begin{array}{l}\mathrm{C}_{16: 1} \mathrm{Cb} \mathrm{Cb} \\
\mathrm{C}_{16: 1} \mathrm{Cb} \mathrm{Cb}\end{array}$ & $\begin{array}{l}\mathrm{OH} \mathrm{OH} \\
\mathrm{Ac}, \mathrm{OH}^{\mathrm{e}}\end{array}$ \\
\hline \multicolumn{10}{|l|}{ Saturated form } \\
\hline Minor components & $\begin{array}{l}1,503.743 \\
1,545.7536\end{array}$ & $\begin{array}{l}1,504.7363(-9) \\
1,546.7471(+3)\end{array}$ & $\begin{array}{l}\text { nd } \\
\text { nd }\end{array}$ & $\begin{array}{l}\text { nd } \\
\text { nd }\end{array}$ & $\begin{array}{c}\text { nd } \\
934.5280(+5)\end{array}$ & $\begin{array}{l}1,137.5845(-16) \\
1,137.5981(-4)\end{array}$ & $\begin{array}{c}\mathrm{nd} \\
1,358.7073(+10)\end{array}$ & $\begin{array}{l}\mathrm{C}_{16: 0} \mathrm{Cb} \mathrm{Cb} \\
\mathrm{C}_{16: 0} \mathrm{Cb} \mathrm{Cb}\end{array}$ & $\begin{array}{l}\mathrm{OH} \mathrm{OH} \\
\mathrm{Ac}, \mathrm{OH}^{\mathrm{e}}\end{array}$ \\
\hline \multicolumn{10}{|c|}{ Mesorhizobium loti R7A } \\
\hline \multicolumn{10}{|l|}{ Unsaturated form } \\
\hline Minor components & $\begin{array}{l}1,415.7157 \\
1,457.7263\end{array}$ & $\begin{array}{l}1,416.7272(+3) \\
1,458.7295(-3)\end{array}$ & $\begin{array}{l}\text { nd } \\
\text { nd }\end{array}$ & $\begin{array}{l}\text { nd } \\
\text { nd }\end{array}$ & $\begin{array}{l}846.4889(-9) \\
846.4889(-9)\end{array}$ & $\begin{array}{l}1,049.5702(-5) \\
1,049.5702(-5)\end{array}$ & $\begin{array}{l}1,270.6600(-4) \\
1,270.6600(-4)\end{array}$ & $\begin{array}{l}\mathrm{C}_{16: 1} \mathrm{OH} \mathrm{OH} \\
\mathrm{C}_{16: 1} \mathrm{OH} \mathrm{OH}\end{array}$ & $\begin{array}{l}\mathrm{OH} \mathrm{OH} \\
\mathrm{Ac}, \mathrm{OH}^{\mathrm{e}}\end{array}$ \\
\hline Major components & $\begin{array}{l}1,458.7216 \\
1,500.7321\end{array}$ & $\begin{array}{l}1,459.7262(-2) \\
1,501.7399(-0)\end{array}$ & $\begin{array}{l}483.3428(-1) \\
483.3004(-10)\end{array}$ & $\begin{array}{l}686.4338(+16) \\
686.4177(-7)\end{array}$ & $\begin{array}{l}889.5087(+7) \\
889.5020(-0)\end{array}$ & $\begin{array}{l}1,092.5959(+13) \\
1,092.5959(+13)\end{array}$ & $\begin{array}{l}1,313.6594(+14) \\
1,313.6741(+2)\end{array}$ & $\begin{array}{l}\mathrm{C}_{16: 1} \mathrm{Cb}, \mathrm{OH}^{\mathrm{e}} \\
\mathrm{C}_{16: 1} \mathrm{Cb}, \mathrm{OH}^{\mathrm{e}}\end{array}$ & $\begin{array}{l}\mathrm{OH} \mathrm{OH} \\
\mathrm{Ac}, \mathrm{OH}^{\mathrm{e}}\end{array}$ \\
\hline \multicolumn{10}{|l|}{ Saturated form } \\
\hline Minor components & $\begin{array}{l}1,417.7314 \\
1,459.742 \\
1,460.7372 \\
1,502.7478\end{array}$ & $\begin{array}{l}1,418.7383(-0) \\
1,460.7546(+4) \\
1,461.7520(+5) \\
1,503.7472(-5)\end{array}$ & $\begin{array}{l}\text { nd } \\
\text { nd } \\
\text { nd } \\
\text { nd }\end{array}$ & $\begin{array}{l}\text { nd } \\
\text { nd } \\
\text { nd } \\
\text { nd }\end{array}$ & $\begin{array}{l}848.5201(+10) \\
848.5201(+10) \\
891.5154(-3) \\
891.5284(+12)\end{array}$ & $\begin{array}{l}1,051.5984(+7) \\
1,051.5984(+7) \\
1,094.6050(+7) \\
1,094.6050(+7)\end{array}$ & $\begin{array}{c}\text { nd } \\
1,272.6812(+0) \\
\text { nd } \\
1,315.6847(-1)\end{array}$ & $\begin{array}{l}\mathrm{C}_{16: 0} \mathrm{OH} \mathrm{OH} \\
\mathrm{C}_{16: 0} \mathrm{OH} \mathrm{OH} \\
\mathrm{C}_{16: 0} \mathrm{Cb}, \mathrm{OH}^{\mathrm{e}} \\
\mathrm{C}_{16: 0} \mathrm{Cb}, \mathrm{OH}^{\mathrm{e}}\end{array}$ & $\begin{array}{l}\mathrm{OH} \mathrm{OH} \\
\mathrm{Ac}, \mathrm{OH}^{\mathrm{e}} \\
\mathrm{OH} \mathrm{OH} \\
\mathrm{Ac}, \mathrm{OH}^{\mathrm{e}}\end{array}$ \\
\hline
\end{tabular}

\footnotetext{
${ }^{a}$ Mass of fragments originating from either in-source fragmentation $\left(\mathrm{B}_{1}-\mathrm{B}_{4}\right)$ or $\beta$-elimination $\left(\mathrm{B}_{5}\right)$; Deviation (in ppm) from theoretical value is indicated; nd $=$ not determined.

${ }^{\mathrm{b}}$ Minor and major Nod factor components produced by Rhizobium spp. Estimates of relative of components amounts obtained from Q-TOF and nuclear magnetic resonance experiments.

${ }^{c}$ Exact theoretical mass obtained from structural formula of Nod factor.

${ }^{\mathrm{d}}$ Mass of singly protonated form.

e These decorations are located at one or the other carbon position. Both decorations are present.
} 

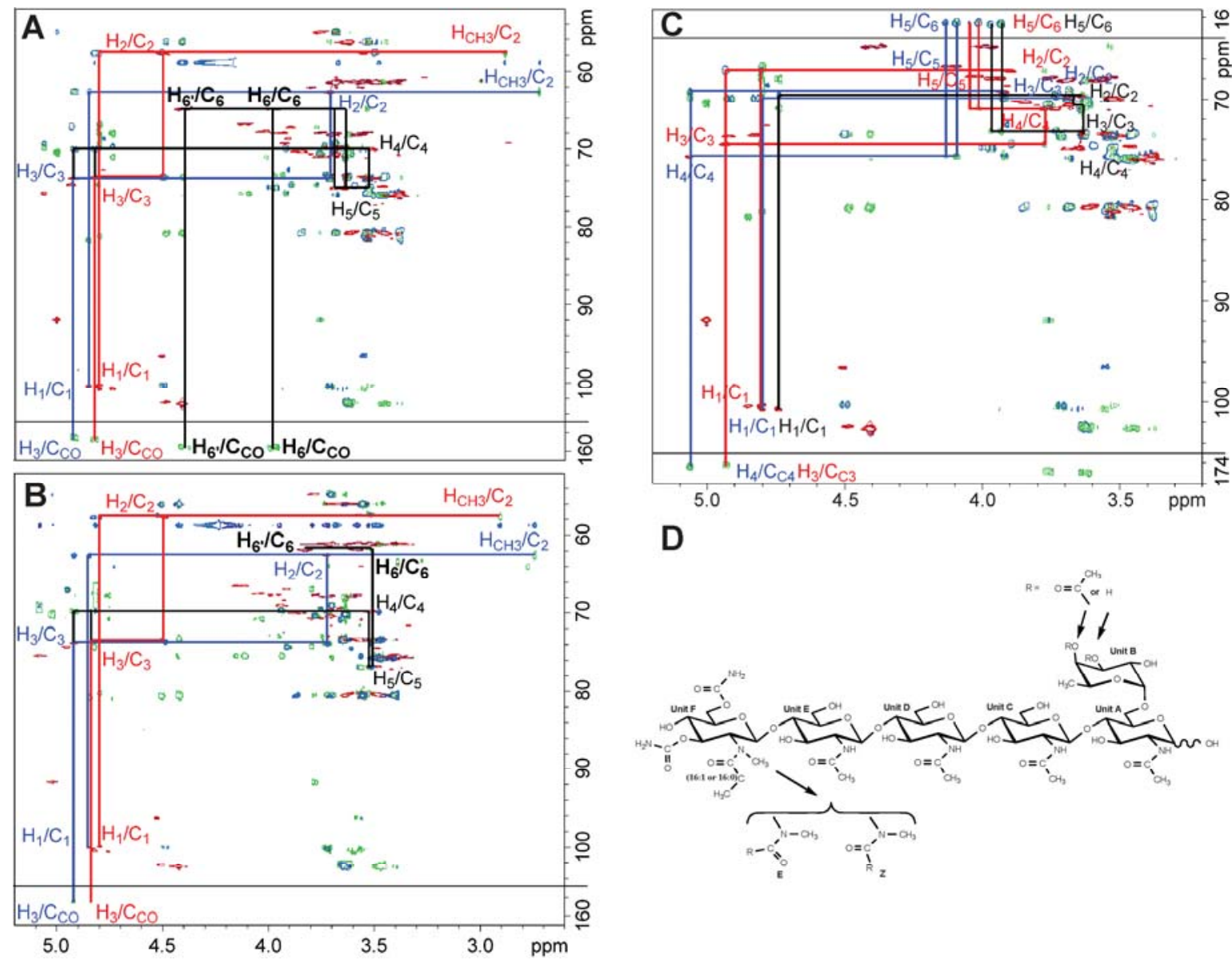

D

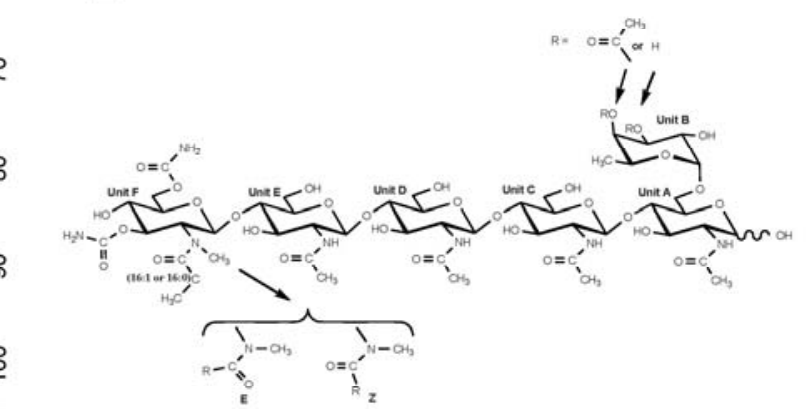

Fig. 4. 2-D C-H correlated nuclear magnetic resonance (NMR) spectra of Nod factors. A and B, Extracted overlay of HSQC (red), HMBC (green), and H2BC (blue) NMR spectra of pyranoside unit F (nonreducing end unit) of Nod factors from A, the Bradyrhizobium sp. (Lotus). and B, Mesorhizobium loti. The secondary amide on C-2 results in the appearance of $(E)$ and $(Z)$ amide rotamers (red and blue assignments, respectively). The assignments of key correlations show the presence two carbamoyl groups at C-3 $(4.845 \mathrm{ppm} / 73.2 \mathrm{ppm}[E]$ and $4.941 \mathrm{ppm} / 73.2 \mathrm{ppm}[Z])$ and C-6 $(4.014+4.397 \mathrm{ppm} / 64.5 \mathrm{ppm}[E]$ and $3.986+4.436 \mathrm{ppm} / 64.5 \mathrm{ppm} \mathrm{[Z])}$ in the Bradyrhizobium sp. (Lotus), whereas only one carbamoyl group at O-3 (4.829 ppm/73.5 ppm [E] and 4.919 $\mathrm{ppm} / 73.7 \mathrm{ppm}[Z]$ ) is present in $M$. loti. These peaks show HMBC correlations to carbamoyl carbonyl groups (lower insets). C, Extracted overlay of HSQC (red), HMBC (green), and H2BC (blue) NMR spectra of unit B (fucosyl unit) of Nod factors from the Bradyrhizobium sp. (Lotus). Assignments of key correlations show the presence of three main species containing either i) one acetyl group at O-3 (3.795 ppm/70.6 ppm, red assignments), ii) one acetyl group at O-4 (5.086 ppm/75.2 ppm, blue assignments), or iii) no acetyl groups (black assignments). M. loti displays identical main species. These acetylated positions show HMBC correlations to O-acetyl carbonyl groups (lower inset). All three species show HMBC correlations to O-6 (top inset). The presence of a single acetyl moiety on either O-3 or O-4 most likely reflects an interconversion between these two forms. D, Chemical structure of identified lipochitin oligosaccharides, monosaccharide units A through $\mathrm{F}$.

Knowing that the amino acid differences between $L$. pedunculatus and L. japonicus are expendable for recognition of the differently carbamoylated Nod factors, we took advantage of the proposed model of NFR5 LysM2 domain (Radutoiu et al. 2007) and mapped the location of the eight differences. Six amino acids are scattered on the surface of the domain and two are located in the proposed Nod factor binding groove. One of them is conserved (V/I125) while the other is changed to a smaller residue (L/S129) (Fig 5C). No differences were located near the leucine 118, which defines specificity toward the nonreducing end of the Nod factor (Radutoiu et al. 2007).

\section{$N f r 1$ and $N f r 5$ are not major determinants of the infection phenotype in Lotus spp.}

Despite the structural differences between Nod factors synthesized by M. loti and Bradyrhizobium sp. (Lotus) and the difference in the amino acid composition of the NFR receptors, both Lotus spp. recognize both microsymbionts and initiate the first steps of nodulation. In order to investigate the possible involvement of LysM-mediated recognition in later symbiotic stages, genetic transformation experiments were performed. First, domain swap chimeric receptors containing the extracel- lular regions of $L$. pedunculatus NFR1 and NFR5 and the corresponding $L$. japonicus kinase domains were constructed (LpjNfrl and LpjNfr5) and tested for complementation of $L$. japonicus $n f r l-1$ and $n f r 5-2$ mutants and the double mutant nfrl-1nfr5-2 using the Agrobacterium rhizogenes transformation system. The chimeric receptors were able to complement the $n f r$ mutant plants; however, no change in the infection phenotype was detected (Fig. 6A and B). Second, A. rhizogenes carrying both LjNfrl and LjNfr5 genes was used to obtain transgenic roots on L. pedunculatus wild-type plants. Composite plants with both wild-type and transformed roots were inoculated with M. loti or the Bradyrhizobium sp. (Lotus) and the symbiotic phenotype was scored. L. pedunculatus plants transformed with LjNfrl and LjNfr5 had a symbiotic phenotype similar to control L. pedunculatus plants when inoculated with M. loti or the Bradyrhizobium sp. (Lotus) (Fig. 6C). The $M$. loti-induced nodules remained uninfected and the plants were nitrogen starved. Moreover, the infection threads formed on the LjNfrl $+L j N f r 5$ transformed roots had a similar occurrence and appearance when compared with the control hairy roots (Supplementary Fig. S7). These results show that the early recognition of rhizobia was not affected by exchanging 
A Lj MKLKTGLLLFFILLLGHVCFHVESNCLKGCDLALASY

LT MKLKTGLLLFFILLLGHVCFHVESNCLKOCDLALASY

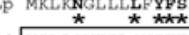

YILPGVF ILQNITTFMQSEIVSSNDAITSYNKDKI LNDINIQSFQRLNIP FPCDCIGGEFLGHVFB

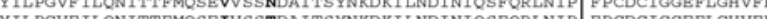
YILPGVFILQNIT:H

YSASKGDTYETIANLYYANLTTVDLLKRFNSYDPRNI PVNAKVNVT VNCSCGNSQVSKDYGLFIT

YKASKGDTYDTIANLYYANLTTVDLLKRFNSYDPENI PVNAKVNVT VNCSCGNSQVSKDYGLFIT

$\frac{\hbar}{\text { YPIRPGDTLQDIANQSSLDAGLIQSFNPSVNFSKDSGIAFIP GRYKNGVYV }}$

YPIRPGDTLQDIANQSSLDAGLIQSFNPSVNFSKDSGIAFI
YPLRPGDTLODIANOSSLDAGLIRSFNPSVNFS KDSGIAFI

YPLRPGDTLQDIANQSSLDAGLIQSFNPSVNFS KDSGIAFIP $\underset{\text { GRDKNGDYV }}{*}$

B Lj MAVFFLTSGSLSLFLALTLLFTNIAARSEKISGPDFSCPVDSPPSCETYVT

LP MAVFFLTSGSLSLFLALTLLFANIAARSEQISGTDFSCPVDSPSCETYV

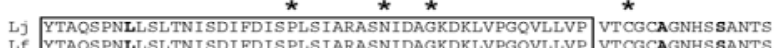

YTAQS PNLLLLTNI I DI FDISPLSIARASNIDAGKDRLVPGQVLLVP VTCGCAGNHSSANTS

YTAQS PNFLSLTNI SDI FDIS PLSIARASNIDAGKDKLVPGQVLLVP VTCGCTGNHSFA

YQIQLGD SYDFVATTLYENLTNWNIVQASNPGVNPYLLPERVKVVFP LFCRCPSKNQLNKGIQYLIT \begin{tabular}{lll} 
YOI I KGD SYDFVATTLYENLTNWNIVQA SNPGVNPYLLPERVKVVFP & LFCRCPSKNQLNKGIQYLIT \\
\hline YQIQLGD SYNFIATT SYYENLTNWNIVQDSNPGVNPYLLPEGI KVVFP & LFCRCPSKNQLNKGIQYLIT
\end{tabular}

YVWKPNDNVSLVSAKFGASPADILTENRYGQDFTAATNLPILIP VTQLPELTQPSSNGRKSSIHLI

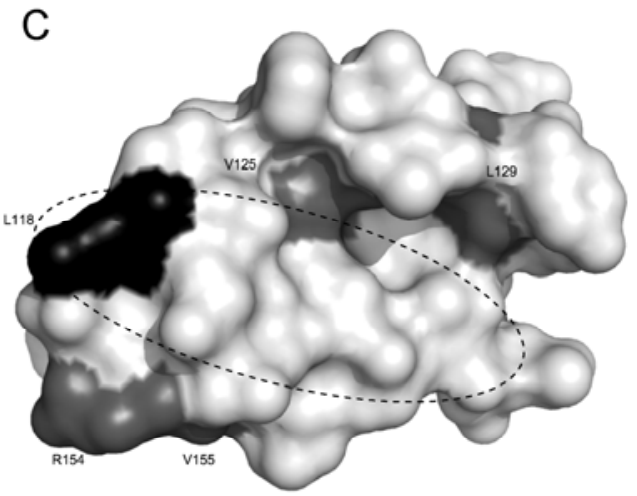

Fig. 5. Alignment of A, NFR1 and B, NFR5 predicted LysM domains from Lotus japonicus, L. filicaulis, and L. pedunculatus. LysM domains are boxed in and amino acid differences are indicated with stars. C, L. japonicus NFR5 LysM2 3D model showing the predicted locations of amino acid differences to L. pedunculatus in gray. The location of the $\mathrm{K} / \mathrm{L}$ difference to L. filicaulis is shown in black and the suggested specificity-determining region is outlined.
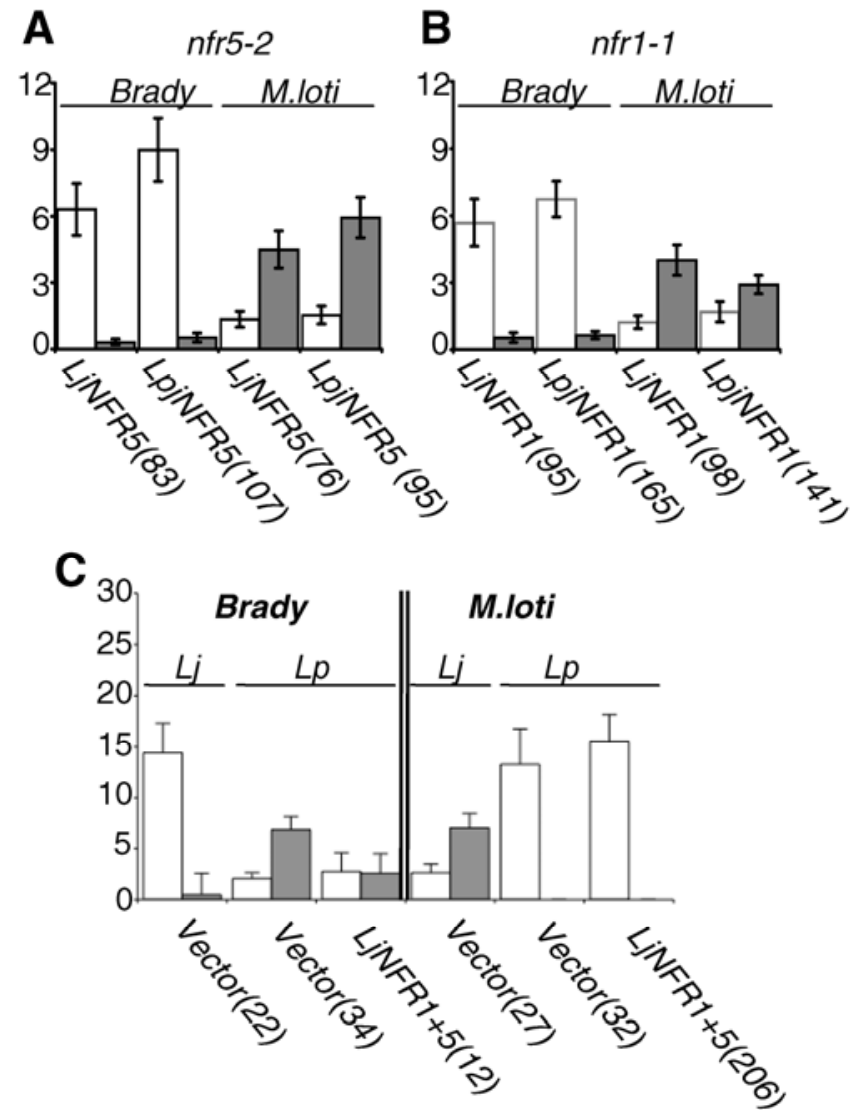

Fig. 6. Chimeric Lpj constructs complement the Lotus japonicus A, nfr5-2 and $\mathbf{B}, n f r 1-1$ plants and the symbiotic phenotypes are similar to mutants complemented with L. japonicus Nfrl or Nfr5 and inoculated with Mesorhizobium loti and a Bradyrhizobium sp. (Lotus). The average number of white (white bars) and pink (gray bars) nodules is shown. C, Symbiotic phenotype of wild-type L. japonicus $(\mathrm{Lj})$ and L. pedunculatus (Lp) transformed roots containing the empty vector (AR12) or the LjNfr $1+L j N f r 5$ and inoculated with M. loti or a Bradyrhizobium sp. (Lotus). Error bars represent the $95 \%$ confidence interval and the number of analyzed plants is shown in parentheses.

L. japonicus and L. pedunculatus extracellular regions of NFR1 or NFR5 or both and allowed us to conclude that the $N f r$ genes alone are unlikely to be the major components determining the infection phenotype in Lotus roots.

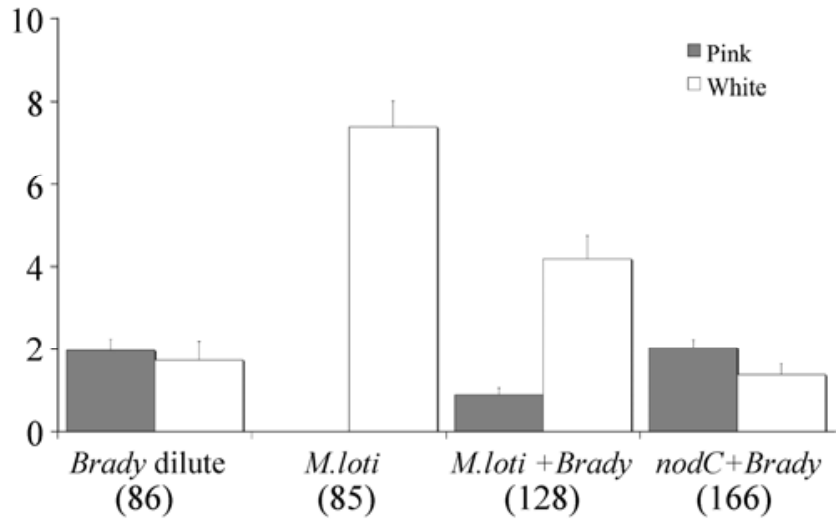

Fig. 7. Competition experiment using mixed inoculation of rhizobial strains. Nodulation phenotype of Lotus pedunculatus inoculated with a 150 to 600 times excess of Mesorhizobium loti. The average number of white and pink nodules is shown in white or black, respectively. Brady dilute $=$ corresponding 150 to 600 times dilution of the Bradyrhizobium sp. (Lotus). nodC $=$ M. loti mutant unable to produce Nod factors. Error bars are $95 \%$ confidence intervals and number of plants analyzed is shown in parentheses.

\section{M. loti infection of $L$. pedunculatus is not rescued by the presence of the compatible symbiont.}

Our complementation experiments conducted in L. pedunculatus and L. japonicus revealed that, apart from Nod factor recognition, one or more other components produced by compatible rhizobia are needed for infection thread progression through the root cortex. In order to investigate whether one or more of such signals produced by Bradyrhizobium sp. (Lotus) could rescue the phenotype of $L$. pedunculatus inoculated with M. loti, a coinoculation experiment was performed (Fig. 7). A mixture of M. loti and the Bradyrhizobium sp. (Lotus), in which $M$. loti was in excess, was applied to $L$. pedunculatus roots. Corresponding dilutions of the two rhizobia were included as controls and the number of white and pink nodules was counted 3 weeks after inoculation. When the Bradyrhizobium sp. (Lotus) was present together with M. loti, the formation of pink nodules was induced; however, their number was significantly reduced compared with the Bradyrhizobium sp. (Lotus) control. These results show that presence of the compatible symbiont Bradyrhizobium sp. (Lotus) did not rescue the M. loti infection, and the L. pedunculatus plants formed a large number of white ineffective nodules. Moreover, the phenotype of 
L. pedunculatus inoculated with a mixture of a $M$. loti mutant unable to produce Nod factor (nodC) and the Bradyrhizobium sp. (Lotus) disclosed a Nod factor-dependent competition between the two bacteria. This indicates that fast- and slow-growing rhizobia compete at the molecular level for infection sites.

\section{DISCUSSION}

We have determined the structure of Nod factors synthesized by the Bradyrhizobium sp. (Lotus) using improved separation techniques and powerful NMR methods. The three major Nod factor species present in approximately equal amounts consist of a pentameric GlcNAc backbone which carries, at the reducing end, a 4-O-fucose with either an acetyl group or a proton in position 3 or 4 , an $\mathrm{N}$-acylated and $\mathrm{N}$-methylated cis-vaccenic acid, and carbamoyl groups in position 3 and 6 at the nonreducing moiety. For comparison, the structure of the $M$. loti Nod factors was determined and this allowed us to unequivocally determine the position of the carbamoyl and O-acetylfucose decorations. Previous analysis suggested these substitutions in position 4 of the fucose and position 4 of the nonreducing moiety (Lopez-Lara et al. 1995), respectively, whereas our structural analysis places them in positions 3 or 4 and position 3, respectively. Therefore, the Bradyrhizobium sp. (Lotus) Nod factor is distinguished from the M. loti synthesized Nod factors by a carbamoyl in position 6 of the nonreducing moiety. Thus, diversity in symbiotic phenotypes of strains nodulating Lotus spp. is reflected in variations in Nod factor structures.

The possible consequences of these Nod factor differences on the symbiotic behavior of the bacterial strains were further characterized by detailed phenotypic analyses, genetic transformation, and complementation experiments. Complementation of Ljnfrl and Ljnfr5 single and double mutants with chimeric LpjNfr receptor constructs showed equivalent perception of M. loti and Bradyrhizobium sp. (Lotus) Nod factors. This shows that individual L. japonicus and L. pedunculatus NFR extracellular regions are interchangeable. Amino acid diversity was previously identified between the L. japonicus and L. filicaulis NFR LysM domains without affecting Nod factor recognition (Radutoiu et al. 2007). By analyzing a more distantly related Lotus sp., our results contribute to the demarcation of amino acids dispensable for Nod factor perception, thus paving the way for detailed understanding of the molecular basis of receptor-Nod factor interaction.

Mapping of the NFR5 LysM2 amino acid differences revealed that two of the variations between $L$. japonicus and $L$. pedunculatus are positioned in the proposed Nod factor binding groove. This groove is located between the first $\beta$-strand and first helix of the domain with the nonreducing end of the Nod factor located close to Leu 118 of L. japonicus (Radutoiu et al. 2007). At position 125, Lp-NFR5-LysM2 had an additional methyl group (V/I) and, at position 129, it was considerably smaller due to the leucine-to-serine difference. How the amino acid changes are accommodated in the three-dimensional structure is difficult to predict accurately but they do suggest that specificity may be determined by the amino acids marked out in Figure 5C. No variations were located in the area previously found to determine specificity toward the nonreducing end, where the carbamoyl difference between $M$. loti and Bradyrhizobium sp. (Lotus) Nod factor is present.

The combined amino acid differences found in the extracellular domains of L. japonicus and L. pedunculatus NFR1 and NFR5 appear not to influence the recognition of the Nod factor substituted with one or two carbamoyls at the nonreducing end. This indicates that these amino acids are unlikely to play a major role in the direct interaction with the Nod factor or other receptor components. Complementation of Ljnfrl and
Ljnfr5 mutants with chimeric Lpj receptors allowed Bradyrhizobium sp. (Lotus) to infect the induced nodules; however, the symbiotic compatibility ceased and early senescence was observed as in the wild type. A similar phenotype was observed for $L$. japonicus in the presence of $R$. etli, which produces Nod factors structurally identical to M. loti (Banba et al. 2001; D'Haeze and Holsters 2002). All together, this shows that, upon Nod factor-NFR recognition, one or more additional checkpoints control the persistence of the symbiotic interaction after symbiosome formation in determinant nodules of Lotus spp.

Transformation of the intact $L$. japonicus receptors into $L$. pedunculatus did not interfere with the normal recognition of the compatible Bradyrhizobium sp. (Lotus) symbiont. However, the arrested infection thread phenotype was not rescued, nor was an increased number of infection events induced by the $M$. loti strain. Lack of infection thread progression in the transformed plants suggest that LjNFR1 or LjNFR5 do most likely not mediate infection thread progression in L. pedunculatus, indicating that additional symbiotic components are required for infection of nodule primordia. Previous studies report the involvement of secreted cyclic $\beta$-glucans and exopolysaccharides during infection thread formation or progression or both (Cheng and Walker 1998; Kawaharada et al. 2007). We tested a possible positive effect of one or more Bradyrhizobium sp. (Lotus)-secreted symbiotic signals on infection of $M$. loti-induced nodules by performing a coinoculation experiment. Our results showed a competition event between the fast- and slow-growing mixed rhizobia for L. pedunculatus root infection sites. Interestingly, the outcome of this competition was found to depend on Nod factor production.

\section{MATERIALS AND METHODS}

\section{Plant material and rhizobial strains.}

L. japonicus ecotype Gifu and L. pedunculatus cv. Maku were used. For transformation experiments, wild-type plants and L. japonicus mutants ( $n f r l, n f r 5$, and $n f r l n f r 5)$ were used (Radutoiu et al. 2003, 2007).

The Bradyrhizobium sp. (Lotus) NZP2309 and $M$. loti NZP2235 were used for phenotypic analyses. The M. loti R7A eGFP was used for infection thread analyses while the $M$. loti R7A and $M$. loti R7A nodC were used for the coinoculation experiments. For Nod factor isolation, the R7A pmp2112 and the Bradyrhizobium sp. (Lotus) NZP2309 pmp2112 were used. The Bradyrhizobium sp. (Lotus) NZP2309 pmp2112 was obtained by bacterial conjugation.

\section{Phenotypic analyses.}

The plants were grown in magenta boxes containing quarterstrength B\&D media as previously described (Radutoiu et al. 2003) and all rhizobial strains were grown in or on YMB media (Sullivan et al. 1995).

For inoculation, $100 \mu \mathrm{l}$ of rhizobia culture (optical density at $580 \mathrm{~nm}\left[\mathrm{OD}_{580}\right]=$ approximately 1.5 ) was added to 1 liter of quarter-strength B\&D media and the nodulation phenotype was assayed 5 weeks postinoculation. For nodulation kinetics experiments, the plants were grown in petri dishes with solid quarter-strength B\&D slants and were inoculated with $100 \mu \mathrm{l}$ of $1 / 100$ dilution of rhizobia culture $\left(\mathrm{OD}_{580}=\right.$ approximately 1.5). The number of nodules on each plant was monitored each week for a period of 13 weeks.

For coinoculation experiments, the Bradyrhizobium sp. (Lo$t u s)$ and $M$. loti were grown to thick precultures $\left(\mathrm{OD}_{600}=\mathrm{ap}-\right.$ proximately 1.5 ) and $200 \mu \mathrm{l}$ of the preculture was added to 5 $\mathrm{ml}$ of fresh media and grown for an additional period (M. loti for $26 \mathrm{~h}$ and the Bradyrhizobium sp. (Lotus) for $42 \mathrm{~h}$ ). The bacteria were spun down $(10 \mathrm{~min}, 2,500 \times g)$ and resuspended 
in water to $\mathrm{OD}_{600}=0.1$. A $10^{-4}$ dilution of each bacterium was plated on three replica plates to perform a viable cell count. A $10^{-2}$ dilution of each bacterium was used for obtaining the mixed inoculums mentioned in Figure 7. Mixed inoculum (1 $\mathrm{ml})$ was applied to 10 plants.

\section{Expression analyses.}

All nodules were harvested from L. japonicus roots inoculated with M. loti or the Bradyrhizobium sp. (Lotus). Total RNA was extracted from nodules and uninoculated roots by a combination of a modified "Hot Borate" method (Wan and Wilkins 1994) and TRIZOL (Sigma-Aldrich). The RNA was DNAse treated using RQ1-DNAse (Promega Corp.). The cDNA synthesis was performed using the reverse transcriptase RevertAid M-MuLV Reverse Transcriptase (Fermentas). The transcript levels of the six nodulin genes and the three housekeeping genes were determined by quantitative realtime PCR as previously described (Radutoiu et al. 2003). The primers used for transcript amplification are presented in Supplementary Table S1. Normalized relative ratios of each nodulin gene and three independent housekeeping genes (TB2C, UBC, and GAPDH) were calculated using the Relative Quantification Software (Roche). The geometric mean of relative expression ratios for three biological and three technical repetitions were calculated and the corresponding upper and lower 95\% confidence intervals were calculated (Vandesompele et al. 2002).

\section{Acetylene reduction assays.}

Acetylene reduction was measured on 10 nodules in $60-\mathrm{ml}$ glass vials containing a 5\% acetylene/air mix. Only pink nodules were analyzed from L. japonicus. A 1-ml gas sample was injected into a gas chromatograph at $0-\mathrm{min}, 30-\mathrm{min}$, and 1-h time points. The concentration of produced ethylene was estimated using an ethylene dilution standard curve.

\section{Microscopic analyses.}

Infection threads were visualized using a Zeiss LSM 510 Meta confocal microscope (488-nm excitation, 505- to 530-BP filter). For each genotype and bacteria combination, the number of infection threads was counted on 1-cm root segments from 21 plants at 4 weeks postinoculation. A total of $50 \mathrm{seg}$ ments was analyzed per combination.

The nodule sections were analyzed by light microscopy. The nodules were stored in $70 \%$ ethanol and then fixed in a glutheraldehyde (1\%)-paraformaldehyde (4\%) mix buffered to $\mathrm{pH}$ 7.8. The nodules were embedded in Technovite 7100 and $5-\mu \mathrm{m}$ sections were stained with $0.1 \%$ toluidine blue or ruthenium red.

Electron microscopy was according to James and Sprent (1999).

\section{Sequencing of L. pedunculatus Nfr1 and Nfr5 and construction of chimeric $N f r$ receptor genes.}

Using specific primers for $N f r l$ and $N f r 5$ genes and L. pedunculatus genomic DNA as template, PCR products of LpNfrI and LpNfr5 were obtained and sequenced. The L. pedunculatus genes were compared with L. japonicus $N f r l$ and Nfr5 (AJ575247 and AJ575254). The PCR-amplified extracellular domains of L. pedunculatus Nfrl (BclI-fw GAAAAATTAATG ATCAAAACCTGGTAG; Dra1-rev CTTCTGGGTTTCATAA TTGATTCTGATG) and Nfr5 (HpaI-fw CCCTCTGATAAAA CACAAGTCCCTTTTC; PpuMI-rev CAGCAGTCTCAGCTG ATGAAGCAGTCC) were used to exchange the corresponding extracellular domains of LjNfrl and LjNfr5 (Madsen et al. 2003; Radutoiu et al. 2003, 2007). The resulting chimeric receptors were introduced into the pIV10 integration vector
(AM235368) that allows integration into the A. rhizogenes strain AR12 (Hansen et al. 1989). Transgenic hairy roots were generated using the A. rhizogenes system (Stougaard et al. 1987; Hansen et al. 1989) and the composite plants were analyzed for the nodulation phenotype 5 weeks postinoculation with M. loti or the Bradyrhizobium sp. (Lotus).

\section{Nod factor isolation and characterization.}

Nod factors extraction and purification. The Nod factors were purified from Bradyrhizobium sp. (Lotus) containing the naringenin inducible nod $\mathrm{D}$ (pMP2112) (Lopez-Lara et al. 1995) grown in YMB media (Hooykaas et al. 1977) supplemented with mannitol (7 g/liter), naringenin $(1 \mu \mathrm{g} / \mathrm{ml})$, and spectinomycin $(100 \mu \mathrm{g} / \mathrm{ml})$. Nod factor extraction from the media was performed using $n$-butanol as previously described (Lopez-Lara et al. 1995). Nod factors were extracted from Mesorhizobium loti grown in minimal media (Poupot et al. 1993). The $n$-butanol was removed by rotary evaporation and the residue resuspended in acetonitrile (aq) and prefractionated by solid-phase extraction on a Varian (Lake Forest, CA, U.S.A.) BondElut C18 extraction column (100 by $4.6 \mathrm{~mm}$ ). This fraction was used for analysis by UPLC-Q-TOF. Further purification was accomplished by HPLC on a semipreparative C18 column (300 ̊, 20 by $180 \mathrm{~mm}$ ) from FeF chemicals A/S (Køge, Denmark).

UPLC-Q-TOF MS analysis of Nod factors and Nod factor derivatives. Analysis of carbohydrates or modified carbohydrates by UPLC was performed on a Waters Acquity UPLC system equipped with 2.1-by-100-mm Waters Acquity BEH Shield $\mathrm{C}_{18}$ column $(1.7-\mu \mathrm{m}$ particle size) and the mobile phases were i) water with $0.1 \%$ formic acid and ii) acetonitrile with $0.1 \%$ formic acid. The UPLC was coupled to a Q-TOF ultima ESI mass spectrometer (Micromass, Ltd., Manchester, U.K.).

NMR analysis. All NMR spectra $\left({ }^{1} \mathrm{H}\right.$ COSY, NOESY [100 $\mathrm{ms}$ mixing time], $\mathrm{HMBC}$, and ${ }^{13} \mathrm{C} \mathrm{HSQC}$ experiments and H2BC-spectra) were recorded on a Bruker Avance 800 spectrometer equipped with a TCI cryoprobe, carrier frequencies 799.40 MHz for proton and 201.02 MHz for carbon.

Bioassay of isolated Nod factor. The bioassay of isolated Nod factor (HPLC peak 1) was performed using the L. japonicus transgenic line carrying an Nin- $\beta$-glucuronidase (GUS) fusion. Seedlings ( 1.5 weeks old) were placed in solutions containing either water or Nod factor $\left(10^{-7} \mathrm{M}\right.$, dissolved in $60 \%$ acetonitrile and diluted in water). After $48 \mathrm{~h}$ of incubation in the dark, the seedlings are assayed for GUS expression according to Kosugi and associates (1990).

A detailed description of the methods used for Nod factor extraction, purification, and analyses is provided in the Supplementary Materials and Methods.

\section{LysM domain modeling.}

The homology model was made according to Radutoiu and associates (2007), and differences between L. japonicus and $L$. pedunculatus were mapped using PyMOL (DeLano WL 2002; DeLano Scientific, San Carlos, CA, U.S.A.).

\section{ACKNOWLEDGMENTS}

We thank C. Ronson, J. Sullivan, and P. Rodpothong (University of Otago, New Zealand) for providing the $M$. loti R7A strains; H. P. Spaink (Leiden University, Netherlands) for providing the R7A pmp2112 strain; and N. J. Nielsen and J. Petersen for technical assistance on UPLC-Q-TOF analyses. The $800 \mathrm{MHz}$ NMR spectra were recorded at the Danish Instrument Centre for NMR Spectroscopy of Biological Macromolecules. This work was supported by the Danish Research Foundation CARB center, the Danish Research Agency-Young Scientists grant (2113-04-0018) and the LOTASSA program. 


\section{LITERATURE CITED}

Arrighi, J. F., Barre, A., Ben Amor, B., Bersoult, A., Soriano, L. C., Mirabella, R., de Carvalho-Niebel, F., Journet, E. P., Gherardi, M., Huguet, T., Geurts, R., Denarie, J., Rouge, P., and Gough, C. 2006. The Medicago truncatula lysine motif-receptor-like kinase gene family includes NFP and new nodule-expressed genes. Plant Physiol. 142:265-279.

Banba, M., Siddique, A. B., Kouchi, H., Izui, K., and Hata, S. 2001. Lotus japonicus forms early senescent root nodules with Rhizobium etli. Mol. Plant-Microbe Interact. 14:173-180.

Cheng, H. P., and Walker, G. C. 1998. Succinoglycan is required for initiation and elongation of infection threads during nodulation of alfalfa by Rhizobium meliloti. J. Bacteriol. 180:5183-5191.

Degtjareva, G. V., Kramina, T. E., Sokoloff, D. D., Samigullin, T. H., Valiejo-Roman, C. M., and Antonov, A. S. 2006. Phylogeny of the genus Lotus (Leguminosae, Loteae): evidence from nrITS sequences and morphology. Can. J. Bot. 84:813-830.

Denarie, J., Debelle, F., and Prome, J. C. 1996. Rhizobium lipo-chitooligosaccharide nodulation factors: signaling molecules mediating recognition and morphogenesis. Annu. Rev. Biochem. 65:503-535.

D'Haeze, W., and Holsters, M. 2002. Nod factor structures, responses, and perception during initiation of nodule development. Glycobiology 12:79R-105R.

Hansen, J., Jorgensen, J. E., Stougaard, J., and Marcker, K. A. 1989. Hairy roots-a short cut to transgenic root nodules. Plant Cell Rep. 8:12-15.

Hooykaas, P. J. J., K. P. M., Nuti, M. P., Schilperoort, R. A., and Rorsch, A. 1977. Transfer of the Agrobacterium tumefaciens Ti plasmid to virulent Agrobacteria and to Rhizobium ex planta. J. Gen. Microbiol. 98:477-484

James, E. K., and Sprent, J. I. 1999. Development of N2-fixing nodules on the wetland legume Lotus uliginosus exposed to conditions of flooding. New Phytol. 142:219-231.

Kawaharada, Y., Eda, S., Minamisawa, K., and Mitsui, H. 2007. A Mesorhizobium loti mutant with reduced glucan content shows defective invasion of its host plant Lotus japonicus. Microbiology 153:39833993.

Kosugi, S., Ohashi, Y., Nakajima, K., and Arai, Y. 1990. An improved assay for beta-glucuronidase in transformed cells: methanol almost completely suppresses a putative endogenous beta-glucuronidase activity. Plant Sci. 70:133-140.

Krusell, L., Krause, K., Ott, T., Desbrosses, G., Kramer, U., Sato, S., Nakamura, Y., Tabata, S., James, E. K., Sandal, N., Stougaard, J., Kawaguchi, M., Miyamoto, A., Suganuma, N., and Udvardi, M. K. 2005. The sulfate transporter SST1 is crucial for symbiotic nitrogen fixation in Lotus japonicus root nodules. Plant Cell 17:1625-1636.

Limpens, E., Franken, C., Smit, P., Willemse, J., Bisseling, T., and Geurts, R. 2003. LysM domain receptor kinases regulating rhizobial Nod factor-induced infection. Science 302:630-633.

Lopez-Lara, I. M., van den Berg, J. D., Thomas-Oates, J. E., Glushka, J., Lugtenberg, B. J., and Spaink, H. P. 1995. Structural identification of the lipo-chitin oligosaccharide nodulation signals of Rhizobium loti. Mol. Microbiol. 15:627-638.

Madsen, E. B., Madsen, L. H., Radutoiu, S., Olbryt, M., Rakwalska, M., Szczyglowski, K., Sato, S., Kaneko, T., Tabata, S., Sandal, N., and Stougaard, J. 2003. A receptor kinase gene of the LysM type is involved in legume perception of rhizobial signals. Nature 425:637-640.

Miflin, B. J., and Habash, D. Z. 2002. The role of glutamine synthetase and glutamate dehydrogenase in nitrogen assimilation and possibilities for improvement in the nitrogen utilization of crops. J. Exp. Bot. 53:979-987.

Ott, T., van Dongen, J. T., Gunther, C., Krusell, L., Desbrosses, G., Vigeolas, H., Bock, V., Czechowski, T., Geigenberger, P., and Udvardi, M. K. 2005. Symbiotic leghemoglobins are crucial for nitrogen fixation in legume root nodules but not for general plant growth and development. Curr. Biol. 15:531-535.

Pacios Bras, C., Jorda, M. A., Wijfjes, A. H., Harteveld, M., Stuurman, N., Thomas-Oates, J. E., and Spaink, H. P. 2000. A Lotus japonicus nodulation system based on heterologous expression of the fucosyl transferase NodZ and the acetyl transferase NoIL in Rhizobium leguminosarum. Mol. Plant-Microbe Interact. 13:475-479.
Petersen, B. O., Vinogradov, E., Kay, W., Wurtz, P., Nyberg, N. T., Duus, J. O., and Sorensen, O. W. 2006. H2BC: a new technique for NMR analysis of complex carbohydrates. Carbohydr. Res. 341:550-556.

Petit, A., Stougaard, J., Kühle, A., Marcker, K. A., and Tempé, J. 1987. Transformation and regeneration of the legume Lotus corniculatus: a system for molecular studies of symbiotic nitrogen fixation Mol. Gen. Genet. 207:245-250.

Poupot, R., Martinez-Romero, E., and Prome, J. C. 1993. Nodulation factors from Rhizobium tropici are sulfated or nonsulfated chitopentasaccharides containing an $\mathrm{N}$-methyl-N-acylglucosaminyl terminus. Biochemistry 32:10430-10435.

Radutoiu, S., Madsen, L. H., Madsen, E. B., Felle, H. H., Umehara, Y., Gronlund, M., Sato, S., Nakamura, Y., Tabata, S., Sandal, N., and Stougaard, J. 2003. Plant recognition of symbiotic bacteria requires two LysM receptor-like kinases. Nature 425:585-592.

Radutoiu, S., Madsen, L. H., Madsen, E. B., Jurkiewicz, A., Fukai, E., Quistgaard, E. M., Albrektsen, A. S., James, E. K., Thirup, S., and Stougaard, J. 2007. LysM domains mediate lipochitin-oligosaccharide recognition and $\mathrm{Nfr}$ genes extend the symbiotic host range. EMBO (Eur. Mol. Biol. Organ.) J. 26:3923-3935.

Schauser, L., Roussis, A., Stiller, J., and Stougaard, J. 1999. A plant regulator controlling development of symbiotic root nodules. Nature 402:191-195.

Schlaman, H. R., Horvath, B., Vijgenboom, E., Okker, R. J., and Lugtenberg, B. J. 1991. Suppression of nodulation gene expression in bacteroids of Rhizobium leguminosarum biovar viciae. J. Bacteriol. 173:4277-4287.

Scott, D. B., Chua, K.-Y., Jarvis, B. D. W., and Pankhurst, C. E. 1985. Molecular cloning of a nodulation gene from fast- and slow-growing strains of Lotus rhizobia Mol. Gen. Genet. 201:43-50.

Sharma, S. B., and Signer, E. R. 1990. Temporal and spatial regulation of the symbiotic genes of Rhizobium meliloti in planta revealed by transposon Tn5-gusA. Genes Dev. 4:344-356.

Smit, P., Limpens, E., Geurts, R., Fedorova, E., Dolgikh, E., Gough, C., and Bisseling, T. 2007. Medicago LYK3, an entry receptor in rhizobial nodulation factor signaling. Plant Physiol. 145:183-191.

Stougaard, J., Petersen, T. E., and Marcker, K. A. 1987. Expression of a complete soybean leghemoglobin gene in root nodules of transgenic Lotus corniculatus. Proc. Natl. Acad. Sci. U.S.A. 84:5754-5757.

Sullivan, J. T., Patrick, H. N., Lowther, W. L., Scott, D. B., and Ronson, C. W. 1995. Nodulating strains of Rhizobium loti arise through chromosomal symbiotic gene transfer in the environment. Proc. Natl. Acad. Sci. U.S.A. 92:8985-8989.

Szczyglowski, K., Hamburger, D., Kapranov, P., and de Bruijn, F. J. 1997. Construction of a Lotus japonicus late nodulin expressed sequence tag library and identification of novel nodule-specific genes. Plant Physiol. 114:1335-1346.

Thykjaer, T., Danielsen, D., She, Q., and Stougaard, J. 1997. Organization and expression of genes in the genomic region surrounding the glutamine synthetase gene Gln1 from Lotus japonicus. Mol. Gen. Genet. 255:628-636.

Vandesompele, J., De Preter, K., Pattyn, F., Poppe, B., Van Roy, N., De Paepe, A., and Speleman, F. 2002. Accurate normalization of real-time quantitative RT-PCR data by geometric averaging of multiple internal control genes. Genome Biol. 3:RESEARCH0034.

Walker, S. A., Viprey, V., and Downie, J. A. 2000. Dissection of nodulation signaling using pea mutants defective for calcium spiking induced by nod factors and chitin oligomers. Proc. Natl. Acad. Sci. U.S.A. 97:13413-13418.

Wan, C. Y., and Wilkins, T. A. 1994. A modified hot borate method significantly enhances the yield of high-quality RNA from cotton (Gossypium hirsutum L.). Anal. Biochem. 223:7-12.

Zhang, X. C., Wu, X., Findley, S., Wan, J., Libault, M., Nguyen, H. T., Cannon, S. B., and Stacey, G. 2007. Molecular evolution of lysin motif-type receptor-like kinases in plants. Plant Physiol. 144:623636.

Zhukov, V., Radutoiu, S., Madsen, L. H., Rychagova, T., Ovchinnikova, E., Borisov, A., Tikhonovich, I., and Stougaard, J. 2008. The pea Sym37 receptor kinase gene controls infection-thread initiation and nodule development. Mol. Plant-Microbe Interact. 21:1600-1608. 